\title{
Exposure to Hazardous Workplace Noise and Use of Hearing Protection Devices Among US Workers-NHANES, 1999-2004
}

\author{
SangWoo Tak, ScD, MPH ${ }^{1} *$ Rickie R. Davis, $\mathrm{PhD}^{2}$ and Geoffrey M. Calvert, MD, MPH
}

\begin{abstract}
Background To estimate the prevalence of workplace noise exposure and use of hearing protection devices (HPDs) at noisy work, NIOSH analyzed 1999-2004 data from the National Health and Nutrition Examination Survey (NHANES).

Methods A total of 9,275 currently employed workers aged $\geq 16$ years were included in the weighted analysis. Hazardous workplace noise exposure was defined as self-reported exposure to noise at their current job that was so loud that the respondent had to speak in a raised voice to be heard. Industry and occupation were determined based on the respondent's current place and type of work.

Results Twenty-two million US workers (17\%) reported exposure to hazardous workplace noise. The weighted prevalence of workplace noise exposure was highest for mining (76\%, $S E=7.0)$ followed by lumber/wood product manufacturing (55\%, SE =2.5). High-risk occupations included repair and maintenance, motor vehicle operators, and construction trades. Overall, 34\% of the estimated 22 million US workers reporting hazardous workplace exposure reported non-use of HPDs. The proportion of noise-exposed workers who reported non-use of HPDs was highest for healthcare and social services $(73.7 \%$, $S E=8.1)$, followed by educational services (55.5\%).

Discussion Hearing loss prevention and intervention programs should be targeted at those industries and occupations identified to have a high prevalence of workplace noise exposure and those industries with the highest proportion of noise-exposed workers who reported non-use of HPDs. Am. J. Ind. Med. 52:358-371, 2009.
\end{abstract}

Published 2009 Wiley-Liss, Inc. ${ }^{+}$

KEY WORDS: noise-induced hearing loss; industry; occupation; national estimates; surveillance; national survey

\section{INTRODUCTION}

Hearing loss caused by work-related noise exposure is referred to as occupational noise-induced hearing loss (NIHL) [Morata and Dunn, 1995]. It is estimated that worldwide,

1Division of Surveillance, Hazard Evaluations, and Field Studies, National Institute for Occupational Safety and Health, Centers for Disease Control and Prevention, Cincinnati, Ohio

${ }^{2}$ Division of Applied Research and Technology, National Institute for Occupational Safety and Health, Centers for Disease Control and Prevention, Cincinnati, Ohio

The findings and conclusions in this report are those of the authors and do not necessarily represent the views of the National Institute for Occupational Safety and Health.

${ }^{*}$ Correspondence to:SangWooTak,ScD,MPH,National Institute for Occupational Safety and Health, 4676 Columbia Parkway, R-17, Cincinnati,0H 45226.E-mail: stak@cdc.gov

Accepted 21 January 2009

D0I 10.1002/ajim.20690. Published online in Wiley InterScience (www.interscience.wiley.com)

Published 2009 Wiley-Liss, Inc.

${ }^{\dagger}$ This article is a US Government work and, as such, is in the public domain in the United States of America.
$16-24 \%$ of hearing impairment is work-related [Nelson et al., 2005]. In the US, NIHL accounted for approximately $11 \%$ of all occupational illnesses reported to the Bureau of Labor Statistics in 2004 and 2005. Within the manufacturing sector, hearing loss - with an incidence rate of 15.7/10,000 full-time workers-was the most commonly reported non-fatal occupational injury [BLS, 2006].

The hearing conservation amendment requiring training and audiometric testing in addition to the original noise 
standard was adopted by OSHA [1983]. In 1981, the U.S. Environmental Protection Agency (EPA) estimated that at least 9 million US workers were occupationally exposed to daily noise levels exceeding $85 \mathrm{~dB}$ [EPA, 1981]. These estimates were derived by searching the scientific literature for noise surveys of workers in various industries (i.e., agriculture, mining, construction, manufacturing, and transportation) and extrapolating the survey findings to the entire workforce in the relevant industry. Note that the survey data used may not have been representative of the true distribution of noise exposure in the relevant industry. More current noise exposure data are available in the Occupational Safety and Health Administration's (OSHA) Integrated Management Information System (IMIS). Middendorf [2004] analyzed the IMIS data from 1979 through 1999 and showed that noise exposures in the manufacturing sector and the services sector decreased during this time period. However, noise exposures measured by federal OSHA during enforcement inspections increased from 1995 to 1999 . IMIS data are too sparse to assess noise exposures in most non-manufacturing sectors, such as construction, trade, transportation, and agriculture. As such, IMIS data cannot be used to generate representative national estimates of hazardous occupational noise exposure. Up-to-date estimates of hazardous workplace noise exposure prevalence are needed.

The most effective means of preventing NIHL is to eliminate the noise hazard [NIOSH, 1996]. While engineering controls of noise exposure are most desirable, in some situations they may be impractical and difficult to implement for a number of reasons, such as cost-effectiveness, lack of enforcement, and management's safety culture. As a consequence, personal protective devices are often the sole means to protect the hearing of workers. Hearing protective devices (HPDs) can work as a short-term solution to prevent NIHL if their use is carefully planned, evaluated, supervised, and consistent [NIOSH, 1998; Arezes and Miguel, 2002]. If engineering controls are insufficient, OSHA requires employers to provide employees with HPDs. Employers are required to "make hearing protectors available to all employees exposed to an 8-hr time-weighted average of $85 \mathrm{~dB}$ or greater at no cost to the employees" (OSHA CFR 1910.95(i)(1)). Davis and Sieber (2002) analyzed data from the 1981 to 1983 NIOSH National Occupational Exposure Survey (NOES) to estimate the percentage of workers wearing some form of hearing protection. Of the estimated 4.1 million industrial workers exposed to hazardous workplace noise, $41 \%$ were wearing some form of hearing protection. Overall, the percentage ranged from $79 \%$ (miscellaneous repair service) to less than $1 \%$ (railroad transportation, communication, wholesale trade, etc.) [Davis and Sieber, 2002]. The data used by Davis and Sieber are now over 25 years old. Recent national estimates of HPD usage among noise-exposed workers are unavailable.
Surveillance of workplace noise exposure is vital to prevention of NIHL because it can identify the most problematic industries and occupations, and because it can be used to evaluate the effectiveness of intervention activities. The objective of the present study was to analyze the National Health and Nutrition Examination Survey (NHANES) data collected from 1999 to 2004 to estimate the prevalence of hazardous workplace noise exposure related to specific industry sectors and occupation categories and to estimate hearing protection usage among workers in those industry sectors and occupation categories.

\section{METHODS}

NHANES, conducted by the National Center for Health Statistics, is a nationally representative survey designed to assess the health and nutritional status of adults and children in the United States through interview and direct physical examination. Beginning in 1999, NHANES became a continuous, annual survey in order to provide more timely data on the health and nutritional status of the population. Participants are interviewed face to face in their homes to obtain information on their health history, health behaviors, risk factors, occupation, and industry using standardized questionnaires. Participants subsequently undergo an additional interview and physical examination at a mobile examination center. The procedures to select the sample and collect information have been described in detail elsewhere [NCHS, 2006a]. For this report, NHANES data collected from 1999 to 2004 (2004 was the most recent year that industry and occupation data were publicly available) were aggregated to increase the precision of the prevalence estimates. During the years 1999-2004, 18,891 adults aged 16 years and older completed the sample interview questionnaire, including 9,275 who were currently employed and included in the analysis. The response rate from 1999 to 2004 among individuals aged $\geq 16$ years was $77.8 \%$ (unweighted).

\section{Occupational Variables}

Each participant provided information on their place of work (industry) and kind of work (occupation). Each individual's current industry of employment was subsequently classified into one of 45 industry categories by NCHS [2006b]. These 45 industry categories were re-grouped into 28 categories to be compatible with the North American Industry Classification System (NAICS, 2002). Each individual's occupation was classified into one of 41 occupation categories by NCHS [2006b, 1997]. For the analysis of occupation by industry, the 28 industry categories were reclassified into eight major industry sectors [NIOSH, 2008].

An individual was considered to be exposed to hazardous workplace noise if they answered affirmatively to the question "At your current job, are you currently exposed to 
loud noise? [By loud noise I mean noise so loud that you have to speak in a raised voice to be heard?]."

To determine the occupation groups at greatest risk of hazardous workplace noise exposure, we identified in each of the eight major industry sectors the top three occupations with the highest prevalence of workplace noise exposure and the top three occupations with the largest number of workers exposed to hazardous noise. Due to the small sample size for many occupations in each major industry sector, we limited our analysis to occupation groups with a sample size of at least 7 (which represents approximately 99,000 US workers). The sample size of 7 was selected a priori, and was considered to be sufficient for analysis.

Among those who reported exposure to hazardous workplace noise, the proportions of workers who reported non-use of HPDs were estimated. Non-use of HPDs was defined as those who answered "No" to the question, "In this (current) job, do you ever wear protective hearing devices?" No followup questions were asked to determine the reasons for non-use. There was insufficient sample size to identify the top three occupations that reported non-use of HPDs in many of the major industry sectors. As such, the 28 industry categories were divided into two major industry sector groups based on our findings related to hazardous workplace noise exposure: high noise prevalence industry group (mining, agriculture, construction, manufacturing, and transportation and warehousing) versus low noise prevalence industry group (wholesale and retail trade; utilities; health care; and services). To determine where the lack of HPD usage was greatest, we identified within each of these two industry groups the occupations having a proportion of workers who reported non-use of HPDs that was higher than the national average. Due to the small sample size for many occupation categories in each industry group, we also limited our analysis to occupation categories with a sample size of at least 7 .

\section{Demographical Variables}

A participant's age was defined as his/her age in years at the time of the household interview, and was categorized into one of five groups. Gender was as noted by the household interviewer. Each individual was placed into one of four race/ ethnicity categories; non-Hispanic white, non-Hispanic black, Hispanic, and other. A dichotomous variable was created for education: respondents with college or higher education (16 years or more), and respondents with less than 16 years of education.

\section{Statistical Analysis}

All analyses were completed using the Software for the Statistical Analysis of Correlated Data (SUDAAN v 9.0) package to take into account sample weights and design effects due to the complex sample survey design [Research
Triangle Institute, 2004]. Variance estimates were adjusted for the population survey units, strata, and sampling weights assigned by NCHS. The weighted population size, prevalence of workplace noise exposure, and proportion of workers who did not wear HPDs in noisy workplaces were estimated by industry and occupation categories. The SUDAAN Loglink program with a Poisson distribution assumption was used to estimate rate ratios (RRs) and the $95 \%$ confidence intervals for non-use of HPDs among workers who reported current hazardous workplace noise exposure by industry adjusted for the effect of age, sex, race, and education. The mining industry was chosen as the reference industry a posteriori because this industry had the lowest proportion of workers who reported non-use of HPDs.

\section{RESULTS}

\section{Hazardous Workplace Noise Exposure}

Of the 9,275 respondents aged $\geq 16$ years who were currently employed at the time of interview, 1,462 (15.8\% of $9,275)$ reported hazardous workplace noise exposure at their current job. Overall, the weighted prevalence of current hazardous workplace noise exposure among employed US workers aged $\geq 16$ years was $17.2 \%$ representing approximately 22.4 million workers out of the estimated 130 million US workers (Table I). Males had a higher prevalence of noise exposure $(26.3 \%)$ than females $(6.7 \%)$. Respondents aged 35-44 showed the highest prevalence of self-reported hazardous workplace noise exposure (19.7\%). The prevalence of hazardous workplace noise exposure was elevated among non-Hispanic whites (18.3\%), and individuals with less than 16 years of education $(22.6 \%)$.

\section{Hazardous noise exposure by industry}

Industry pertains to the place of work. Table II provides the estimated proportion of workers exposed to hazardous workplace noise for each of 28 industry categories and a subtotal for the all manufacturing sub-sectors. The five industries with the highest proportion of workers reporting exposure to workplace noise at their current job were: mining (75.8\%); lumber and wood product manufacturing (55.4\%); rubber, plastics, and leather products $(48.0 \%)$; utilities (46.1\%); and repair and maintenance $(45.1 \%)$. The prevalence of hazardous workplace noise exposure among workers in each of the manufacturing industry sub-sectors was higher than the national average proportion (17.2\%) and ranged from $21 \%$ (electrical machinery, equipment, and supplies) to $55 \%$ (lumber and wood products including furniture). The manufacturing industry had the greatest number of workers exposed to hazardous workplace noise exposure (estimated number of exposed workers, 5.7 million, or $25 \%$ of all US workers exposed to hazardous 
TABLE I. Prevalence (\%) of Hazardous Workplace Noise Exposure Among Current Workers by Selected Characteristics—NHANES Subjects Aged 16 or Older, United States, 1999-2004 $(\mathrm{n}=9,275)$

\begin{tabular}{|c|c|c|c|c|c|}
\hline Characteristic & $\begin{array}{l}\text { No. in } \\
\text { sample }\end{array}$ & $\begin{array}{c}\text { Population } \\
\text { estimate }^{\mathbf{a}}(\%)\end{array}$ & $\begin{array}{l}\text { No. of workers } \\
\text { exposed in sample }\end{array}$ & $\begin{array}{l}\text { Estimated no. of } \\
\text { exposed workers }\end{array}$ & $\begin{array}{c}\text { Estimated } \\
\text { prevalence }^{\mathrm{d}} \text { (SE) }\end{array}$ \\
\hline Total & 9,275 & $130.3(100.0)$ & 1,462 & 22.4 & $17.2(0.7)$ \\
\hline \multicolumn{6}{|l|}{ Gender } \\
\hline Male & 5,003 & $71.2(54.6)$ & 1,161 & 18.5 & $26.3(1.0)$ \\
\hline Female & 4,272 & $59.1(45.4)$ & 301 & 3.9 & $6.7(0.6)$ \\
\hline \multicolumn{6}{|l|}{ Race/ethnicity } \\
\hline Non-Hispanic white & 4,219 & $91.8(70.5)$ & 713 & 16.8 & $18.3(0.8)$ \\
\hline Mexican American and other Hispanic & 2,786 & $18.2(13.9)$ & 468 & 3.0 & $16.7(1.1)$ \\
\hline Non-Hispanic black & 1,899 & $13.8(10.6)$ & 238 & 1.8 & $12.7(0.9)$ \\
\hline Other race including multiracial & 371 & $6.5(5.0)$ & 43 & 0.8 & $12.6(2.3)$ \\
\hline \multicolumn{6}{|l|}{ Age (years) } \\
\hline $16-24$ & 2,439 & $21.1(16.2)$ & 325 & 3.2 & $15.0(1.2)$ \\
\hline $25-34$ & 1,883 & $29.8(22.9)$ & 314 & 5.4 & $18.1(1.1)$ \\
\hline $35-44$ & 1,874 & $33.4(25.6)$ & 361 & 6.6 & $19.7(1.1)$ \\
\hline $45-54$ & 1,624 & $29.2(22.4)$ & 291 & 5.4 & $18.4(1.4)$ \\
\hline $55+$ & 1,455 & $16.8(12.9)$ & 171 & 1.9 & $11.4(1.2)$ \\
\hline \multicolumn{6}{|l|}{ Education } \\
\hline 16 years or more & 4,216 & $55.8(42.8)$ & 519 & 9.9 & $13.2(0.8)$ \\
\hline Less than 16 years & 5,059 & $74.5(57.2)$ & 943 & 12.6 & $22.6(0.9)$ \\
\hline
\end{tabular}

SE, standard error.

${ }^{\mathrm{a} E s t i m a t e d ~ n u m b e r ~ o f ~ U S ~ w o r k e r s ~ i n ~ m i l l i o n s . ~}$

${ }^{\mathrm{b}}$ Number of respondents who reported hazardous workplace exposure in sample.

${ }^{\mathrm{c}}$ Estimated number of US workers who are exposed to hazardous workplace noise in millions.

${ }^{\mathrm{d}}$ per 100.

workplace noise), followed by construction (4.5 million) and retail trade (2.1 million).

\section{Occupations with a high prevalence of noise exposure}

For each of the major industry sector groups, Table III shows both the top three occupations with the highest prevalence of hazardous workplace noise exposure and the top three occupations with the greatest number of workers exposed to hazardous workplace noise. It is noteworthy that the occupation groups with the highest prevalence are not always the same groups with the greatest number of exposed workers. In manufacturing, vehicle and mobile equipment mechanics and repairers showed the highest prevalence $(82 \%)$ of hazardous workplace noise exposure. This occupation was also among the top three in prevalence in two other industries: wholesale and retail trade, and services. The construction trade occupations were present in the top three lists of three industries: construction; transportation, warehousing, and utilities; and services. Interestingly, the prevalence of hazardous workplace noise exposure was lower among construction trades workers employed in construction (49.5\%) compared to those employed in transportation, warehousing, and utilities (75.8\%) but was equivalent to those employed in services (49.5\%).

\section{Non-Use of Hearing Protection Devices}

The 1,458 respondents who reported hazardous workplace noise exposure and who provided industry information were included in this analysis. A total of $530(36.4 \%$, unweighted) respondents reported non-use of HPDs in their current noisy workplace. Overall, the weighted proportion of noise-exposed US workers who never used HPDs was $34.3 \%$-representing approximately 7.7 million workers out of the estimated 22 million US workers who are exposed to hazardous workplace noise (Table IV). Non-HPD usage was greater among females (49.3\%) compared to males $(31.1 \%)$, the youngest age group (40\%), and persons with less than 16 years of education $(36.3 \%)$. 
TABLE II. Estimated Population Prevalence of Hazardous Workplace Noise Exposure by Industrial Sector-NHANES Subjects Aged 16 or Older, United States, 1999-2004 $(n=9,275)$

\begin{tabular}{|c|c|c|c|c|c|}
\hline Industry sector [NAICS, 2002] & $\begin{array}{l}\text { No. in } \\
\text { sample }\end{array}$ & $\begin{array}{c}\text { Population } \\
\text { estimate }^{\mathrm{a}}(\%)\end{array}$ & $\begin{array}{l}\text { No. of workers } \\
\text { exposed in } \\
\text { sample }^{b}\end{array}$ & $\begin{array}{c}\text { Estimated } \\
\text { no. of exposed } \\
\text { workers }^{c}\end{array}$ & $\begin{array}{c}\text { Estimated } \\
\text { prevalence } \\
\text { (\%)/(SE) }\end{array}$ \\
\hline Agriculture, Forestry, and Fishing (11) & 354 & $3.6(2.7)$ & 122 & 1.5 & $43.3(4.7)$ \\
\hline Mining (21) & 41 & $0.8(0.6)$ & 30 & 0.6 & $75.8(7.0)$ \\
\hline Utilities (22) & 90 & $1.5(1.1)$ & 35 & 0.7 & $46.1(7.4)$ \\
\hline Construction (23) & 745 & $10.4(8.0)$ & 277 & 4.5 & $43.5(2.1)$ \\
\hline \multicolumn{6}{|l|}{ Manufacturing $(31-33)^{d}$} \\
\hline Food and kindred products (311-312) & 171 & $1.9(1.4)$ & 74 & 0.7 & $36.1(3.4)$ \\
\hline Textile mill, apparel, and other finished textile products (313-315) & 74 & $0.8(0.6)$ & 18 & 0.2 & $25.9(5.7)$ \\
\hline Rubber, plastics, and leather products $(316,326)$ & 64 & $0.7(0.5)$ & 24 & 0.3 & $48.0(9.2)$ \\
\hline Lumber and wood products, including furniture $(321,337)$ & 84 & $1.0(0.8)$ & 42 & 0.6 & $55.4(2.5)$ \\
\hline Paper products, printing, publishing, and allied industries (322-323) & 129 & $2.0(1.5)$ & 45 & 0.9 & $43.9(6.3)$ \\
\hline Chemicals, petroleum, and coal products (324-325) & 69 & $1.2(1.0)$ & 15 & 0.3 & $22.2(5.7)$ \\
\hline Metal industries (331-332) & 107 & $1.6(1.2)$ & 51 & 0.7 & $44.5(5.5)$ \\
\hline Machinery, except electrical (333) & 111 & $2.1(1.6)$ & 25 & 0.5 & $22.3(4.4)$ \\
\hline Electrical machinery, equipment, and supplies (334-335) & 91 & $1.7(1.3)$ & 16 & 0.4 & $21.5(3.4)$ \\
\hline Transportation equipment (336) & 149 & $2.5(1.9)$ & 64 & 0.9 & $37.8(4.9)$ \\
\hline Miscellaneous (339) & 98 & $1.2(1.0)$ & 26 & 0.3 & $26.9(3.7)$ \\
\hline Wholesale trade (42) & 241 & $4.0(3.1)$ & 30 & 0.6 & $14.1(2.9)$ \\
\hline Retail trade (44-45) & 1,940 & $22.1(17.0)$ & 152 & 2.1 & $9.5(0.9)$ \\
\hline Transportation and warehousing (48-49) & 338 & $5.1(3.9)$ & 77 & 1.3 & $26.1(4.1)$ \\
\hline Finance, insurance, and real estate (51-53) & 1,167 & $18.7(14.4)$ & 72 & 1.1 & $6.0(0.8)$ \\
\hline Professional, scientific, and technical services (54) & 389 & $6.8(5.2)$ & 19 & 0.4 & $5.6(1.9)$ \\
\hline Educational services (61) & 633 & $9.7(7.5)$ & 47 & 0.8 & $8.2(1.4)$ \\
\hline Health care and social services (62) & 1,122 & $16.2(12.4)$ & 40 & 0.6 & $3.5(0.6)$ \\
\hline Arts, entertainment, and recreation (71) & 197 & $2.5(1.9)$ & 43 & 0.5 & $21.5(3.7)$ \\
\hline Accommodation and food service (72) & 150 & $1.9(1.5)$ & 11 & 0.1 & $7.4(1.9)$ \\
\hline Repair and maintenance (811) & 145 & $2.0(1.5)$ & 55 & 0.9 & $45.1(5.7)$ \\
\hline Personal service (812) & 143 & $1.8(1.4)$ & 11 & 0.1 & $7.0(1.9)$ \\
\hline Private households (814) & 99 & $1.1(0.9)$ & 3 & 0.1 & $12.3(5.7)$ \\
\hline Public administration (92) & 296 & $5.0(3.8)$ & 34 & 0.6 & $12.8(1.9)$ \\
\hline All other and not specified & 38 & $0.4(0.3)$ & 4 & 0.1 & $15.5(6.1)$ \\
\hline Total & 9,275 & $130.3(100.0)$ & 1,462 & 22.4 & $17.2(0.7)$ \\
\hline
\end{tabular}

SE, standard error.

a Estimated number of US workers in millions.

${ }^{\mathrm{b}}$ Number of respondents who reported hazardous workplace exposure in sample.

${ }^{\mathrm{c}}$ Estimated number of US workers who are exposed to hazardous workplace noise in millions.

${ }^{\mathrm{d}}$ In all manufacturing sub-sectors combined, the number of noise-exposed workers is 5.7 million, and the prevalence of workplace noise exposure is $36.8 \%$.

\section{Industry}

Among workers with hazardous workplace noise at their current job, the proportion who reported non-use of HPDs was highest for healthcare and social services (74\%) followed by educational services $(56 \%)$, other services $(55 \%)$, and finance, insurance, and real estate (54\%) (Table IV, Fig. 1). The construction industry had the greatest number of noiseexposed workers who reported non-use of HPDs (estimated number of noise-exposed workers who do not use HPDs = $1,409,000)$, followed by manufacturing $(1,364,000)$ and retail trade $(1,080,000$ workers). The adjusted RR for non-use of HPDs was highest for health care and social services $(\mathrm{RR}=5.2,95 \% \mathrm{CI}: 2.4-11.4)$, followed by educational services $(\mathrm{RR}=4.1,95 \% \mathrm{CI}: 1.9-9.0)$. The figure shows that non-use of HPDs among noise-exposed workers is often inversely related to the prevalence of hazardous workplace in the industry as a whole. 


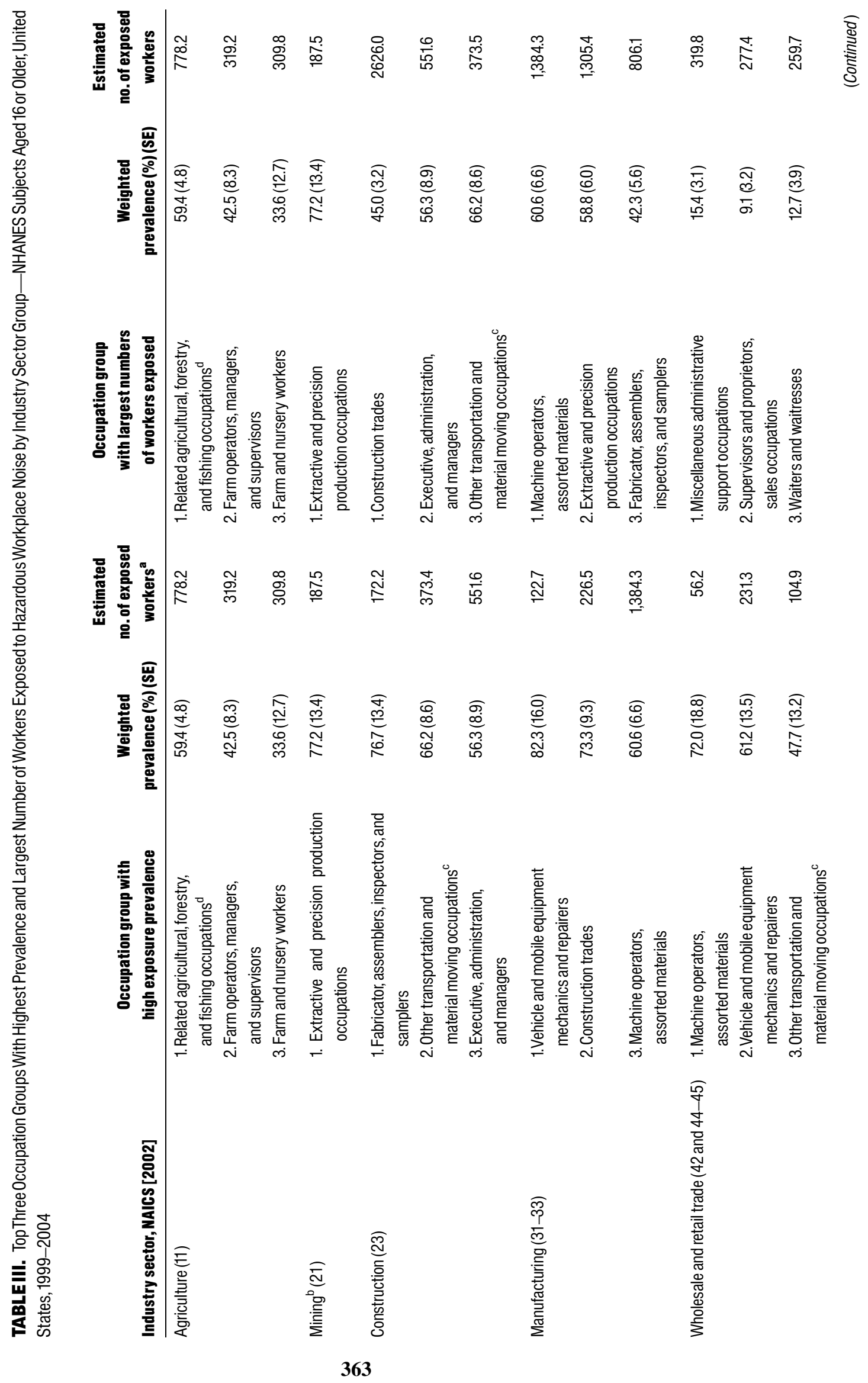




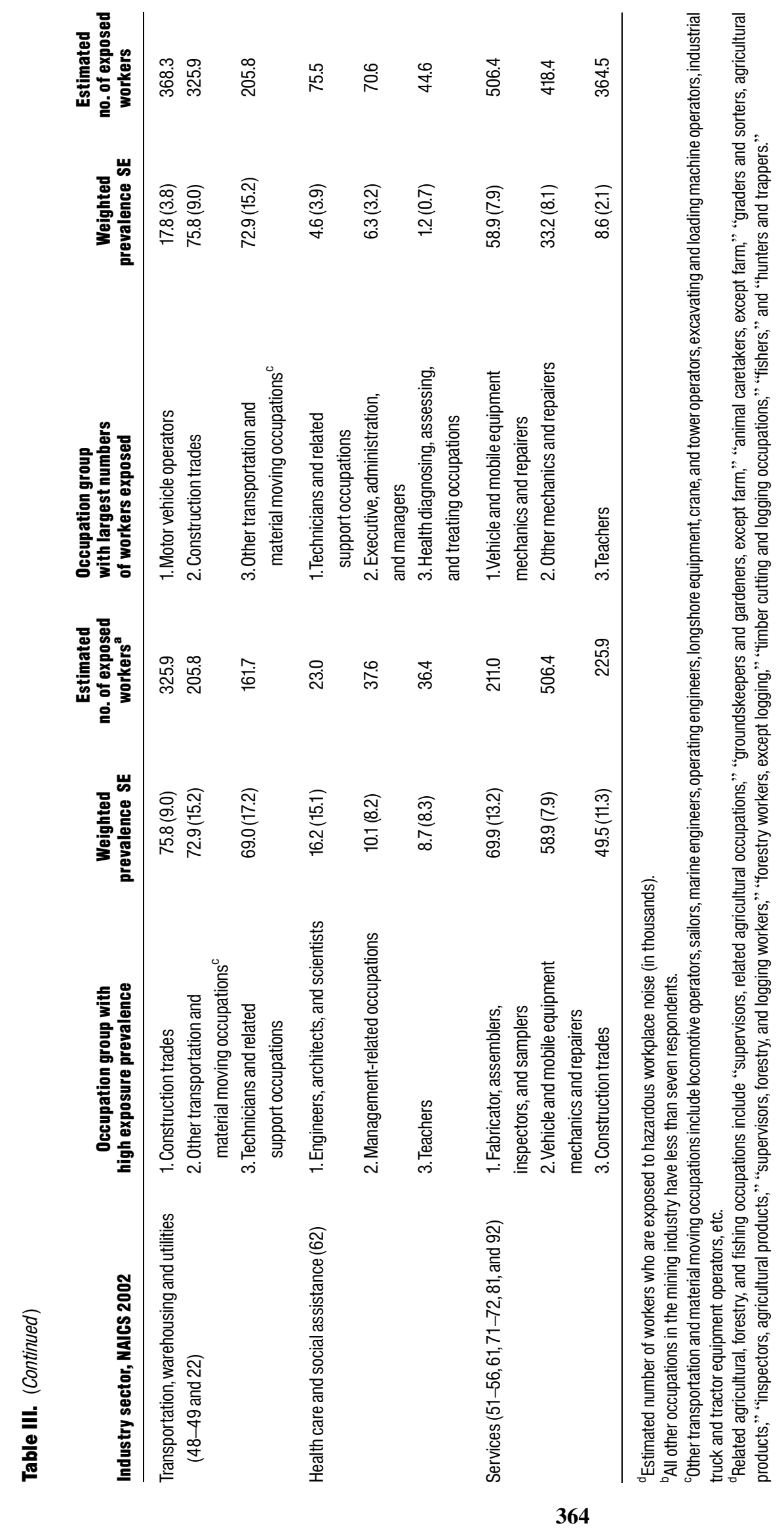


TABLE IV. Estimated Proportion (\%) and Rate Ratios of Workers Not Wearing HPDs in Hazardous Workplace Noise by Industrial Sectors and Other Characteristics, NHANES Subjects Aged 16 or Older, United States, 1999-2004 $(n=1,458)$

\begin{tabular}{|c|c|c|c|c|c|}
\hline & $\begin{array}{c}\text { Noise } \\
\text { exposed } \\
\text { in sample }\end{array}$ & $\begin{array}{c}\text { Non-use of } \\
\text { HPDs in sample }\end{array}$ & $\begin{array}{c}\text { Weighted } \\
\text { number of } \\
\text { non-users of HPDs }{ }^{a}\end{array}$ & $\begin{array}{c}\text { Weighted } \\
\text { proportion of } \\
\text { non-use of HPDs } \\
\text { (\%)/(SE) }\end{array}$ & $\begin{array}{l}\text { Adjusted rate } \\
\text { ratio }(95 \% \text { Cl })^{b}\end{array}$ \\
\hline Total & 1,458 & 530 & 7,674 & $34.3(1.8)$ & \\
\hline \multicolumn{6}{|l|}{ Sex } \\
\hline Male & 1,158 & 390 & 5,737 & $31.1(2.0)$ & 1.00 \\
\hline Female & 300 & 140 & 1,937 & $49.3(4.8)$ & $1.29(0.96-1.73)$ \\
\hline \multicolumn{6}{|l|}{ Race/ethnicity } \\
\hline Non-Hispanic white & 711 & 261 & 5,664 & $33.7(2.2)$ & 1.00 \\
\hline Mexican American and other Hispanic & 467 & 166 & 1,084 & $35.7(3.4)$ & $1.06(0.81-1.38)$ \\
\hline Other race — including multiracial & 43 & 15 & 263 & $31.9(3.0)$ & $1.06(0.66-1.71)$ \\
\hline Non-Hispanic black & 237 & 88 & 664 & $37.9(3.6)$ & $1.06(0.81-1.37)$ \\
\hline \multicolumn{6}{|l|}{ Age (years) } \\
\hline $16-24$ & 324 & 141 & 1,266 & $40.0(4.2)$ & $1.17(0.86-1.59)$ \\
\hline $25-34$ & 313 & 109 & 1,795 & $33.3(2.6)$ & $1.04(0.78-1.38)$ \\
\hline $35-44$ & 359 & 131 & 2,223 & $33.9(3.2)$ & $1.02(0.79-1.33)$ \\
\hline $45-54$ & 291 & 89 & 1,674 & $31.2(3.4)$ & 1.00 \\
\hline $55+$ & 171 & 60 & 716 & $37.5(5.4)$ & $1.11(0.83-1.48)$ \\
\hline \multicolumn{6}{|l|}{ Education } \\
\hline 16 years or more & 517 & 177 & 3,107 & $31.6(2.6)$ & 1.00 \\
\hline Less than 16 years & 941 & 353 & 4,567 & $36.3(2.9)$ & $1.28(1.03-1.61)$ \\
\hline \multicolumn{6}{|l|}{ Industry sector [NAICS, 2002] } \\
\hline Agriculture, forestry, and fishing (11) & 122 & 44 & 408 & $26.6(5.1)$ & $1.90(0.88-4.12)$ \\
\hline Mining (21) & 30 & 5 & 76 & $12.9(4.3)$ & Ref. \\
\hline Utilities (22) & 35 & 7 & 134 & $19.7(10.7)$ & $1.63(0.57-4.71)$ \\
\hline Construction (23) & 277 & 98 & 1,409 & $31.1(3.1)$ & $2.38(1.16-4.87)$ \\
\hline \multicolumn{6}{|l|}{ Manufacturing $(31-33)^{c}$} \\
\hline Food and kindred products (311-312) & 74 & 6 & 89 & $13.3(6.1)$ & $0.88(0.27-2.84)$ \\
\hline Textile mill, apparel, and other finished textile products (313-315) & 18 & 5 & 63 & $30.7(13.9)$ & $1.95(0.68-5.53)$ \\
\hline Rubber, plastics, and leather products $(316,326)$ & 24 & 7 & 83 & $25.1(11.0)$ & $1.88(0.61-5.79)$ \\
\hline Lumber and wood products, including furniture $(321,337)$ & 42 & 10 & 99 & $17.6(7.3)$ & $1.30(0.49-3.48)$ \\
\hline Paper products, printing, publishing, and allied industries (322-323) & 45 & 10 & 175 & $19.9(7.0)$ & $1.45(0.62-3.38)$ \\
\hline Chemicals, petroleum, and coal products (324-325) & 15 & 4 & 75 & $27.3(15.6)$ & $2.16(0.60-7.72)$ \\
\hline Metal industries (331-332) & 51 & 12 & 96 & $13.5(5.0)$ & $0.96(0.36-2.58)$ \\
\hline Machinery, except electrical (333) & 25 & 8 & 148 & $32.3(9.1)$ & $2.47(1.00-6.07)$ \\
\hline Electrical machinery, equipment, and supplies (334-335) & 16 & 6 & 145 & $38.7(14.4)$ & $2.93(1.03-8.35)$ \\
\hline Transportation equipment (336) & 64 & 17 & 267 & $28.4(6.6)$ & $2.16(0.96-4.85)$ \\
\hline Miscellaneous (339) & 26 & 8 & 125 & $37.7(11.6)$ & $2.68(1.02-7.00)$ \\
\hline Wholesale trade (42) & 30 & 16 & 264 & $47.2(13.1)$ & $3.34(1.37-8.17)$ \\
\hline Retail trade (44-45) & 152 & 82 & 1,080 & $51.5(7.4)$ & $3.63(1.75-7.52)$ \\
\hline Transportation and warehousing (48-49) & 77 & 23 & 440 & $33.3(8.0)$ & $2.57(1.13-5.81)$ \\
\hline Finance, insurance, and real estate (51-53) & 72 & 39 & 608 & $53.9(7.2)$ & $4.15(1.96-8.75)$ \\
\hline Professional, scientific, and technical services (54) & 19 & 8 & 140 & $36.5(15.2)$ & $2.86(0.89-9.20)$ \\
\hline Educational services (61) & 47 & 26 & 443 & $55.5(8.6)$ & $4.12(1.89-8.96)$ \\
\hline Health care and social services (62) & 40 & 27 & 415 & $73.7(8.1)$ & $5.19(2.37-11.40)$ \\
\hline Arts, entertainment, and recreation (71) & 43 & 16 & 143 & $26.3(8.6)$ & $1.88(0.66-5.38)$ \\
\hline Repair and maintenance (811) & 55 & 25 & 389 & $42.9(6.3)$ & $3.30(1.53-7.11)$ \\
\hline Other services $(72,81)$ & 25 & 14 & 220 & $54.5(15.4)$ & $3.34(1.35-8.28)$ \\
\hline Public administration (92) & 34 & 7 & 143 & $22.3(6.5)$ & $1.78(0.72-4.39)$ \\
\hline
\end{tabular}

${ }^{a}$ Estimated population who reported not wearing HPDs in their current job (in thousands).

${ }^{\mathrm{b}}$ Rate ratios and the $95 \% \mathrm{Cls}$ (confidence interval) were adjusted for all other variables.

'In all manufacturing sub-sectors combined, the number of noise-exposed workers who never wear HPDs in their current job is 1.36 million, the proportion of non-HPD usage is $23.8 \%$, and the rate ratio is $1.73(95 \% \mathrm{Cl}$ : $0.88,3.40)$. 


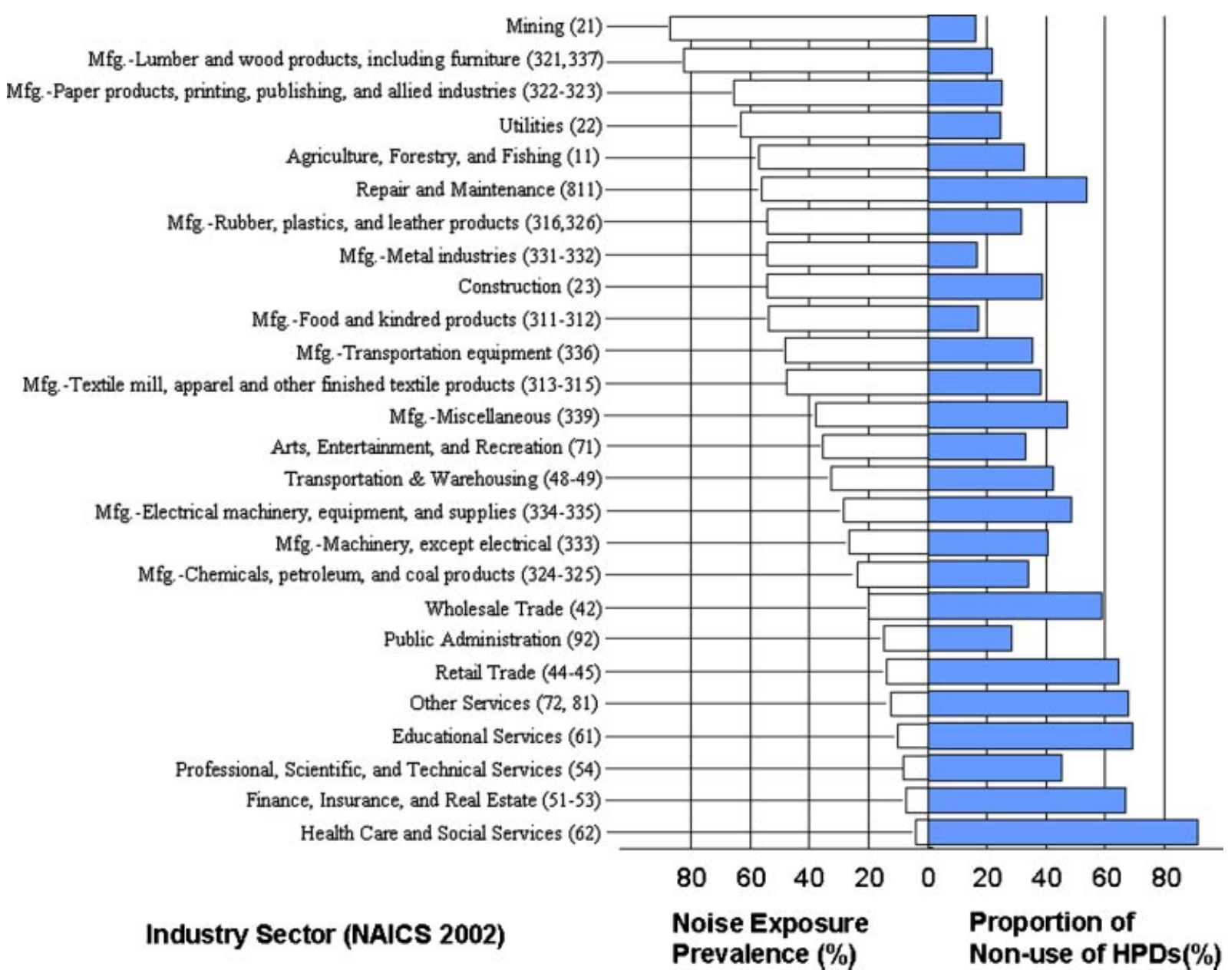

FIGURE 1. Prevalence of current hazardous workplace noise exposure and the estimated proportions of exposed workers who reported non-use of HPDs by industry category —NHANES, United States, 1999-2004. [Color figure can be viewed in the online issue, which is available at www.interscience.wiley.com.]

\section{Occupation}

For both the high and low noise prevalence industry groups, Table $\mathrm{V}$ shows occupations with a proportion of workers who reported non-use of HPDs exceeding the national average of $34 \%$. Overall, noise-exposed workers employed in industries with high noise prevalence were less likely to report non-use of HPDs (28\%) than noise-exposed workers employed in industries with low noise prevalence $(46 \%)$.

In the high noise prevalence industry group, cleaning and building service occupations showed the highest proportion $(63 \%)$ of workers who reported non-use of HPDs. Of the low noise prevalence industry group, personal service occupations showed the highest proportion $(80 \%)$ of workers who reported non-use of HPDs when exposed to hazardous workplace noise, followed by textile, apparel, and furnishing machine operators $(78 \%)$, and technicians and related support occupations $(71 \%)$. It is notable that there were several noise-exposed white collar occupations with high proportions of workers who reported non-use of HPDs, such as: supervisors and proprietors, sales occupations (52\%); teachers (51\%); and executive, administrators, and managers (46\%). Noise-exposed cooks (66\%) and waiters and waitresses $(41 \%)$ also commonly reported non-use of HPDs.

\section{DISCUSSION}

In the absence of a national hazard surveillance system for tracking workplace noise exposure that provides comprehensive and quantitative data on noise exposure levels, selfreported estimates of workplace noise exposure could be very useful in setting priorities for research and prevention efforts. To our knowledge, this is the first study to provide nationally representative estimates of the prevalence of workplace noise exposure by industry since 1981. Our report also provides estimates of the extent of the problem of lack of usage of HPDs among workers exposed to hazardous workplace noise. 
TABLE V. Occupation Groups Whose Proportion of Workers Who Reported Non-Use of HPDs in Their Current Job Was Higher Than the National Average (34\%) by Industry Risk Group_-NHANES Subjects Aged 16 or Older, United States, 1999-2004

\begin{tabular}{|c|c|c|c|c|c|}
\hline & Occupation group & $\begin{array}{c}\text { Noise } \\
\text { exposed } \\
\text { in sample }\end{array}$ & $\begin{array}{l}\text { Non-use } \\
\text { of HPDs } \\
\text { in sample }\end{array}$ & $\begin{array}{c}\text { Weighted } \\
\text { number of } \\
\text { non-use of HPDs }{ }^{a}\end{array}$ & $\begin{array}{c}\text { Weighted } \\
\text { proportion of } \\
\text { non-use of HPDs } \\
(\%) /(\text { SE) }\end{array}$ \\
\hline \multirow[t]{7}{*}{ High noise prevalence industries ${ }^{b}$} & Cleaning and building service occupations & 8 & 3 & 41 & $63.1(24.3)$ \\
\hline & Miscellaneous administrative support occupations & 10 & 4 & 79 & $55.0(17.1)$ \\
\hline & Laborers, except construction & 7 & 3 & 48 & $53.9(18.0)$ \\
\hline & Motor vehicle operators & 27 & 13 & 215 & $50.1(12.3)$ \\
\hline & Other helpers, equipment cleaners, hand packagers, and laborers & 26 & 7 & 97 & $40.9(16.3)$ \\
\hline & Construction laborers & 35 & 14 & 119 & $38.2(10.1)$ \\
\hline & Subtotal $^{d}$ & 961 & 288 & 4,086 & $28.0(1.8)$ \\
\hline \multirow[t]{21}{*}{ Low noise prevalence industries ${ }^{c}$} & Personal service occupations & 18 & 12 & 103 & $80.0(9.5)$ \\
\hline & Textile, apparel, and furnishing machine operators & 11 & 6 & 78 & $77.9(12.8)$ \\
\hline & Technicians and related support occupations & 13 & 10 & 210 & $71.2(13.6)$ \\
\hline & Motor vehicle operators & 16 & 9 & 157 & $67.9(12.8)$ \\
\hline & Cooks & 11 & 8 & 79 & $65.6(17.2)$ \\
\hline & Cleaning and building service occupations & 26 & 16 & 212 & $56.6(12.5)$ \\
\hline & Miscellaneous food preparation and service occupations & 26 & 16 & 195 & $56.1(12.7)$ \\
\hline & Vehicle and mobile equipment mechanics and repairers & 17 & 10 & 142 & $54.8(15.1)$ \\
\hline & Fabricators, assemblers, inspectors, and samplers & 10 & 6 & 79 & $53.4(21.2)$ \\
\hline & Supervisors and proprietors, sales occupations & 16 & 10 & 169 & $52.1(16.1)$ \\
\hline & Freight, stock, and material movers & 12 & 7 & 71 & $52.0(19.5)$ \\
\hline & Sales workers, retail and personal services & 28 & 15 & 124 & $51.7(12.8)$ \\
\hline & Teachers & 20 & 11 & 203 & $50.6(12.3)$ \\
\hline & Other transportation and material moving occupations & 9 & 6 & 83 & $49.8(20.1)$ \\
\hline & Executive, administrators, and managers & 35 & 16 & 290 & $45.5(8.8)$ \\
\hline & Miscellaneous administrative support occupations & 22 & 12 & 105 & $41.7(12.5)$ \\
\hline & Extractive and precision production occupations & 13 & 5 & 129 & $41.2(15.2)$ \\
\hline & Waiters and waitresses & 15 & 7 & 133 & $40.8(14.4)$ \\
\hline & Construction trades & 27 & 12 & 188 & $37.3(11.7)$ \\
\hline & Protective service occupations & 24 & 7 & 132 & $37.0(11.1)$ \\
\hline & Subtotal $^{d}$ & 497 & 242 & 3,588 & $46.1(3.5)$ \\
\hline
\end{tabular}

${ }^{\mathrm{a}}$ Estimated number of workers who are not wearing HPDs in their current job (in thousands).

${ }^{\mathrm{b}}$ High noise prevalence industries include agriculture, mining, construction, manufacturing, and transportation.

${ }^{\mathrm{C}}$ Low noise prevalence industries include all other industries. Military and unknown industry are excluded from the analysis.

${ }^{\mathrm{d}}$ The subtotals include all eligible workers in each industry group, and not just those eligible workers whose occupation group had a non-HPD use proportion that exceeded the national average.

Our analysis showed that nearly one of six US workers (17\%) is exposed to workplace noise that is loud enough that they had to raise their voice to be heard. It is known that the need to raise one's voice usually occurs when the ambient noise level is above $85 \mathrm{dbA}$ [Ahmed et al., 2004]. We also found that one of three US workers exposed to such noise also reported nonuse of HPDs (34\%). The findings indicate that occupational exposure to noise is still a widespread problem that calls for renewed efforts to institute effective occupational hearing loss prevention programs to reduce workplace noise exposures. Occupational hearing loss prevention programs should focus not only on reducing noise exposure but also on increasing the proper use of HPDs where engineering control of noise is unfeasible. Increasing proper use of HPDs may require more effective training, an enhanced workplace safety climate/ culture, and ready availability of comfortable HPDs designed to permit appropriate communication.

\section{Workplace Noise Exposure}

Our estimate of the proportion of workers exposed to hazardous noise exposure was similar to the proportion estimated by the NOES. NOES was conducted by NIOSH from 1981 to 1983 on a probability sample of approximately 
5,000 workplaces across the US. This study estimated that $16.9 \%$ of workers were exposed to workplace noise at or above $85 \mathrm{dBA}$ [Davis and Sieber, 2002]. However, the findings from the NOES must be interpreted cautiously. Many industry sectors were not included in the survey including agricultural production, mining (with the exception of oil and gas extraction), finance, insurance, and real estate, and public administration. We found that some of these excluded sectors had a noise exposure prevalence that exceeded the overall mean prevalence for all workplaces (i.e., agricultural production, and mining), and others were below (i.e., finance, insurance, and real estate, and public administration). NIOSH conducted a similar survey from 1972 to 1974 , called the National Occupational Hazard Surveillance (NOHS). This survey estimated that $13.3 \%$ of US workers were exposed to noise $>85 \mathrm{dBA}$ [CDC, 1988]. In NOHS, the lumber and wood manufacturing industry had the highest proportion of workers exposed to loud noise $(54 \%)$. In NOES, the proportion of workers exposed to loud noise in this industry was estimated to be $41.3 \%$. In our study, the proportion was $55.4 \%$, and similar to the NOHS estimate. All three surveys found that for most manufacturing industries the proportion of workers exposed to loud noise was greater than the prevalence of loud noise exposure among all workers combined. It is notable that the prevalence of workplace noise exposure in the construction industry was lower in the NOHS (29.1\%) and the NOES (17.5\%), whereas we estimated $45.4 \%$ of construction workers were exposed to workplace noise. However, our findings with respect to construction are consistent with another recent investigation. The number of US construction workers exposed to potentially hazardous levels of noise (greater than $90 \mathrm{~dB}$ ) has previously been estimated to be about 4.7 millions [Hattis, 1998]. This is similar to the approximately 4.5 million construction workers whom we estimate to be exposed to workplace noise loud enough to require a raised voice to be heard. Even though NOHS and NOES data are not completely comparable to NHANES selfreport data, it is possible that the prevalence of noise exposure among construction workers has increased during the past two decades due to the increased use of mechanized heavy construction equipment and tools.

We found in our study that workers in agriculture, forestry, and fishing industry had a high prevalence of exposure to hazardous workplace noise (43.3\%). Farm operators and managers have high noise exposures from operating or working in proximity to farm equipment (e.g., $91 \mathrm{~dB}$ for tractors) [Beckett et al., 2000], and working in or around animal confinement facilities (e.g., $87 \mathrm{~dB}$ for sheep farming and $90 \mathrm{~dB}$ in swine confinement facilities) [McBride et al., 2003; Humann et al., 2005]. Some data are available on noise exposures aboard fishing vessels. One recent study of two American commercial fishing vessels found that nearly all workers were exposed to high levels of noise that exceed the exposure limits ( $90 \mathrm{dBA})$ specified by OSHA, but dropped to
$50 \%$ of workers when HPD use was taken into account [Neitzel et al., 2006]. Considering the high prevalence of noise exposure among workers in these industries, interventions to prevent hearing loss should be developed to address the unique needs of the agriculture, fishing, and forestry industry sectors.

Many of the same industries and occupations found to have a high prevalence of hazardous noise exposure were also found in a previous study to have a high prevalence of hearing difficulty [Tak and Calvert, 2008]. Tak and Calvert [2008] examined data from the National Health Interview Survey for the years 1997-2003, in which the prevalence of self-reported hearing difficulty among the US working population was estimated to be $11.4 \%$. An elevated prevalence of hearing difficulty was found in several industries, including: mining; manufacturing; construction; agriculture; forestry and fishing; railroads, utilities; trucking service and warehousing; and repair services. Interestingly, although a high rate of hazardous noise exposure was found in the arts, entertainment, and recreation industry $(21.5 \%)$, the rate of hearing difficulty in that industry was relatively low $(8.8 \%)$.

Our study found that the mining industry has the highest prevalence of hazardous workplace noise exposure among all industrial sectors (76\%). Although few miners reported non-use of HPDs, a previous study found that miners have a very high prevalence of hearing difficulty $(24 \%)$ [Tak and Calvert, 2008], suggesting that further efforts are needed to protect workers' hearing in this industry. Transportation and material moving occupations (other than motor vehicle operators) in the transportation, warehousing, and utilities industry showed the second highest prevalence of noise exposure. Although this occupational group is broad and includes many different occupations, the result supports the findings of a previous study. Tak and Calvert [2008] reported that operators in the railroad industry had the second highest prevalence of hearing difficulty (36\%) compared to all other occupation-industry pairs. Noise exposures and hearing loss among rail yard and railway workers have been long understudied. Our results further justify the need to both confirm the magnitude of noise exposure and prevent hearing loss in the transportation industry, and in railroads in particular. The repair and maintenance service industry is also at high risk of workplace noise exposure. To our knowledge, there is no study specifically addressing noise exposure levels among workers employed in this industry. Note that this industry does not include all establishments that do repair and maintenance. For example, a large amount of repair is done by establishments in the manufacturing, construction, and transportation sectors. Mechanics and repairers are also captured as an occupation category (i.e., vehicle and mobile equipment mechanics and repairers). This occupation was often found to have among the highest prevalence of hazardous workplace noise exposure (Table III). Tak and Calvert [2008] reported that mechanics and repairers employed in 
certain industries (e.g., manufacturing, transportation and communication, and public administration) had among the highest risk of self-reported hearing difficulty compared to workers employed in the finance, insurance, and real estate industries. Further surveillance and intervention efforts should be focused on this industry and occupational group of workers.

\section{Non-Use of Hearing Protective Devices}

The most effective way to prevent NIHL is to remove the hazardous noise from the workplace or to remove the worker from the hazardous noise. Implementation of engineering and administrative controls of noise represents a top occupational health and safety priority and should be fully utilized to reduce hazardous noise exposures [NIOSH, 1996, 1998]. HPDs can be an important temporary tool to reduce noise exposures until effective engineering or administrative controls are instituted. However, the high proportion of workers reporting hazardous workplace noise exposure suggests that engineering noise controls have not been optimally implemented in US workplaces. Currently, HPDs all too often represent the last resort against hazardous noise. In these unfortunate situations, proper use of HPDs should be promoted through more effective training, an enhanced workplace safety climate/culture, and ready availability of comfortable HPDs designed to permit appropriate communication.

Regrettably, we found that workers all too often are not using HPDs when exposed to hazardous noise. Several explanations have been proposed for non-use of HPDs. These include lack of knowledge on the effectiveness of HPDs to reduce noise exposure [Melamed et al., 1996; McCullagh et al., 2002], lack of self-efficacy on HPD usage (i.e., lack of confidence in their ability to correctly use HPDs) [Lusk et al., 1999], concern that HPDs may impair ability to communicate with supervisors and co-workers [Morata et al., 2001; McCullagh et al., 2002], discomfort [Morata et al., 2005], and lack of availability of HPDs [Reilly et al., 1998]. Recent NIOSH data demonstrated that barriers to HPDs may largely be classified into five categories. These are referred to as the " $5 \mathrm{Cs}$ ": Comfort, Convenience, Cost, Communication (which includes the ability to hear all important sounds, not just speech), and Climate, that is, the safety culture/climate [Stephenson, 2009]. Stephenson [2009] concluded that failure to identify and address the specific barriers present in a given workplace will diminish the effectiveness of any HPD education program. Furthermore, a recent Cochrane review provided only limited evidence of the effectiveness of interventions to promote the wearing of HPDs [RP El Dib et al., 2006]. The authors suggested that more research is needed to identify effective methods to enhance the use of HPDs, especially in workplaces where the prevalence of HPD usage is already relatively high.
While the results of this study regarding self-report of non-HPD usage cannot be generalized to estimate the proportion of workers who use HPD consistently and correctly, our findings provide useful baseline information regarding the proportion of non-HPD usage by industry sector and occupation category. Since the present study estimated the proportion of non-HPD usage among those exposed to hazardous noise, unknown is the proportion of workers who use HPDs appropriately. Therefore, the actual number of workers who are not properly protected by HPDs could be much higher than the estimates produced by our study.

We found that non-use of HPDs among noise-exposed workers is often inversely related to the prevalence of hazardous workplace noise exposure in the industry as a whole. For example, several industries with a relatively low prevalence of workplace noise exposure (e.g., retail trade, healthcare and social services, and educational services) had high rates of non-use of HPDs among their noise-exposed workers (Fig. 1). HPD information for the occupations found in these low-risk/noise prevalence industries is available in Table V. Some of the occupations in these low-risk industries are generally known to be at risk of occupational hearing loss, such as machine operators, motor vehicle operators, and mechanics and repairers [Jayjock and Levin, 1984; Sulkowski et al., 1999; Hong, 2005]. These traditionally high-risk occupations can be targeted by hearing loss prevention programs within each of these low noise prevalence industries. However, other occupations are not often thought of as having high workplace noise exposure (such "non-traditional" occupations include cooks, cleaning workers, sales workers, teachers, managers). We found that noise-exposed workers in these service occupations often had a high rate of non-HPD usage. To the best of our knowledge, no noise or HPD research has been conducted on workers in such occupations in lowrisk industries, such as retail, healthcare, information, and educational services. NOES data from 1981 to 1983 also support our findings. The use of HPDs among noise-exposed workers was lowest in health services $(98 \%)$, personal services $(99 \%)$, communication ( $>99 \%$ ), wholesale trade nondurable goods ( $>99 \%$ ), whereas their noise exposure prevalence was lower than most other industries [Davis and Sieber, 2002].

The finding that the prevalence of hearing difficulty among many of these non-traditional noise-exposed occupations is relatively low [Tak and Calvert, 2008] suggests that the noise exposures may be of short duration and/or of low intensity. More research is needed on these vulnerable occupation groups within these low noise prevalence industries to confirm our noise exposure findings and to provide information for the hearing loss prevention programs that serve these noise-exposed workers.

In contrast, a previous study found that aluminum industry workers with higher workplace noise exposures had less hearing loss than co-workers in less noisy areas 
[Rabinowitz et al., 2007]. The authors suggested that this finding could be due to the increased use of HPDs by workers with higher workplace noise exposures. In other words, where higher noise exposures are present employers may strictly enforce HPD usage and irritation from the noise may motivate workers to wear HPDs, compared to workers working in areas with lower, less-irritating noise exposure.

Other studies on HPD usage have been conducted among workers in a limited number of industries, including agriculture [Carpenter et al., 2002; McCullagh et al., 2002], manufacturing [Lusk et al., 1995, 2003], construction [Lusk et al., 1999; Hong, 2005; Neitzel and Seixas, 2005], and firing ranges [Murphy and Tubbs, 2007]. These studies focused on the effectiveness of HPDs or the factors associated with the use of HPDs. Even though a few of them reported the proportions of non-use of HPDs among exposed workers such as 56\% among farmers [McCullagh et al., 2002], 10\% among plant workers [Lusk et al., 1995], and 14\% among construction workers [Neitzel and Seixas, 2005], participants of these studies are likely not representative for either their industry or their occupation. As such, these findings cannot be generalized to the entire nation.

In contrast to a previous study [Lusk et al., 1997], we found that women workers are less likely to wear HPDs than male workers after controlling for other factors including industry. Our study subjects are a representative sample of US workers and therefore, include many other non-industrial workers, such as cashers, waitresses/waiters, social workers, etc. Perhaps, in these non-industrial workers, women are much less likely to wear HPDs, which may have led to a significant difference between male and female workers in the combined multiple regression analysis.

\section{Limitations}

Our study has several limitations. First, workplace noise exposure data in this report are crude self-reported assessments and were not validated with noise surveys. Errors might arise due to the potential inaccuracy of self-report. In a study of manufacturing workers, analysis of perceived and measured noise exposure demonstrated relatively low sensitivity of a one-item self-report of noise exposure (noise loud enough to require a raised voice to be heard); $68 \%$ of workers correctly self-reported exposures to noise levels found to be in excess of $85 \mathrm{~dB}$ [Ahmed et al., 2004]. Therefore, prevalence of workplace noise exposure in this study may have been underestimated due to low sensitivity of the question used to define hazardous workplace noise exposure. However, it is also possible that the prevalence of hazardous workplace noise exposure may have been overestimated since the question used in this survey does not reveal the duration of exposure (i.e., daily hours of noise exposure). Second, the question used to determine hazardous noise exposure prevalence referred to the worker's inability to communicate, implying a continuous noise. Thus, this finding probably cannot be extended to that of a work environment consisting mainly of impulsive noise, such as gun shots or intermittent noise. Third, our crude assessment cannot detect historical reductions in noise exposures that still exceed $85 \mathrm{~dB}$. For example, the present study cannot detect decreases in noise from 95 to $90 \mathrm{~dB}$ which while significant, would continue to be too loud for comfortable communication. As such, although a comparison of NOES data with ours suggests that the prevalence of hazardous noise exposure was unchanged or increased from the early 1980 s to the present, it is possible that reductions in noise exposure could have occurred.

\section{RECOMMENDATIONS AND CONCLUSIONS}

NIOSH [1998] has recommended a national framework for the prevention of occupational hearing loss. NIOSH recommends that hearing loss prevention programs be implemented for all workers whose unprotected 8-hr TWA exposures (i.e., exposures incurred without the use of hearing protectors) equal or exceed $85 \mathrm{dBA}$ and that the programs include at least the following components [NIOSH, 1998]: (1) initial and annual audits of procedures, (2) assessment of noise exposures, (3) engineering or administrative control of noise exposures, (4) audiometric evaluation and monitoring of workers' hearing, (5) use of hearing protectors for exposures equal to or greater than $85 \mathrm{dBA}$, regardless of exposure duration, (6) education and motivation of workers, (7) record keeping, and (8) program evaluation for effectiveness. Our findings suggest that workers in some industries are exposed to high noise levels and this strengthens the need for effective workplace-based hearing loss prevention programs. Furthermore, surveillance systems to track occupational noise exposure and NIHL in an ongoing and systematic manner should be established at the federal and state level.

In conclusion, the present analysis of NHANES data showed that workers in certain industries and occupations are at an increased risk of hazardous workplace noise exposure. Some workers with high noise exposures are employed in industries whose overall noise exposure is perceived as low. Such workers could also benefit from more targeted training programs focusing on the hazards of noise exposure and the efficacy of HPDs. Our findings strengthen the arguments for both more effective reduction/prevention of workplace noise exposure and more targeted hearing loss prevention programs that are specific to the characteristics of these industries and occupation groups.

\section{ACKNOWLEDGMENTS}

We would like to thank Drs. Marie Haring Sweeney, Thais Morata, Mark Stephenson, and Sally Lusk for their helpful comments. The authors have no competing financial interest. 


\section{REFERENCES}

Ahmed HO, Dennis JH, Ballal SG. 2004. The accuracy of self-reported high noise exposure level and hearing loss in a working population in Eastern Saudi Arabia. Int J Hyg Environ Health 207:227-234.

Arezes PM, Miguel AS. 2002. Hearing protectors acceptability in noisy environments. Ann Occup Hyg 46:531-536.

Beckett WS, Chamberlain D, Hallman E, May J, Hwang SA, Gomez M, Eberly S, Cox C, Stark A. 2000. Hearing conservation for farmers: Source apportionment of occupational and environmental factors contributing to hearing loss. J Occup Environ Med 42:806-813.

BLS. 2006. Workplace injuries and illnesses in 2005. Washington, DC:United States Department of Labor.

Carpenter WS, Lee BC, Gunderson PD, Stueland DT. 2002. Assessment of personal protective equipment use among Midwestern farmers. Am J Ind Med 42:236-247.

CDC. 1988. Self-reported hearing loss among workers potentially exposed to industrial noise-United States. MMWR 37(10):158,164-167.

Davis RR, Sieber WK. 2002. Hearing protector use in noiseexposed workers: A retrospective look at1983. AIHA J (Fairfax, Va) 63:199-204.

EPA. 1981. Noise in America: The extent of the noise problem. EPA Report No. 550/9-81-101. U.S. Environmental Protection Agency, Washington, DC.

Hattis D. 1998. Occupational noise sources and exposure in construction industries. Hum Ecol Risk Assess 4:1417-1441.

Hong O. 2005. Hearing loss among operating engineers in American construction industry. Int Arch Occup Environ Health 78:565-574.

Humann MJ, Donham KJ, Jones ML, Achutan C, Smith BJ. 2005. Occupational noise exposure assessment in intensive swine farrowing systems: Dosimetry, octave band, and specific task analysis. J Agromedicine 10:23-37.

Jayjock MA, Levin L. 1984. Health hazards in a small automotive body repair shop. Ann Occup Hyg 28:19-29.

Lusk SL, Ronis DL, Kerr MJ. 1995. Predictors of hearing protection use among workers: Implications for training programs. Hum Factors 37: 635-640.

Lusk SL, Ronis DL, Baer LM. 1997. Gender differences in blue collar workers' use of hearing protection. Women Health 25:69-89.

Lusk SL, Hong OS, Ronis DL, Eakin BL, Kerr MJ, Early MR. 1999. Effectiveness of an intervention to increase construction workers' use of hearing protection. Hum Factors 41:487-494.

Lusk SL, Ronis DL, Kazanis AS, Eakin BL, Hong O, Raymond DM. 2003. Effectiveness of a tailored intervention to increase factory workers' use of hearing protection. Nurs Res 52:289-295.

McBride DI, Firth HM, Herbison GP. 2003. Noise exposure and hearing loss in agriculture: A survey of farmers and farm workers in the Southland region of New Zealand. J Occup Environ Med 45:1281-1288.

McCullagh M, Lusk SL, Ronis DL. 2002. Factors influencing use of hearing protection among farmers: A test of the pender health promotion model. Nurs Res 51:33-39.

Melamed S, Rabinowitz S, Feiner M, Weisberg E, Ribak J. 1996. Usefulness of the protection motivation theory in explaining hearing protection device use among male industrial workers. Health Psychol 15:209-215.

Middendorf PJ. 2004. Surveillance of occupational noise exposures using OSHA's Integrated Management Information System. Am J Ind Med 46:492-504.
Morata TC, Dunn DE. 1995. Occupational hearing loss. Occup Med State Art Rev 10:641-656.

Morata TC, Fiorini AC, Fischer FM, Krieg EF, Gozzoli L, Colacioppo S. 2001. Factors affecting the use of hearing protectors in a population of printing workers. Noise Health 4:25-32.

Morata TC, Themann CL, Randolph RF, Verbsky BL, Byrne DC, Reeves ER. 2005. Working in noise with a hearing loss: Perceptions from workers, supervisors, and hearing conservation program managers. Ear Hear 26:529-545.

Murphy WJ, Tubbs RL. 2007. Assessment of noise exposure for indoor and outdoor firing ranges. J Occup Environ Hyg 4:688-697.

NCHS. 1997. Instruction Manual Part 19: Industry and Occupation Coding for Death Certificates. U.S. Dept. of Health \& Human Services, Centers for Disease Control \& Prevention, National Center for Health Statistics, Division of Vital Statistics.

NCHS. 2006a. Analytic and reporting guidelines: The National Health and Nutrition Examination Survey (NHANES). Hyattsville, MD: National Center for Health Statistics, Centers for Disease Control and Prevention.

NCHS. 2006b. NHANES 1999-2000 Data Documentation, Household Interview Sample Person Questionnaire. Hyattsville, MD:U.S. Dept. of Health \& Human Services. Centers for Disease Control \& Prevention, National Center for Health Statistics, Division of Vital Statistics.

Neitzel R, Seixas N. 2005. The effectiveness of hearing protection among construction workers. J Occup Environ Hyg 2:227-238.

Neitzel RL, Berna BE, Seixas NS. 2006. Noise exposures aboard catcher/ processor fishing vessels. Am J Ind Med 49:624-633.

Nelson DI, Nelson RY, Concha-Barrientos M, Fingerhut M. 2005. The global burden of occupational noise-induced hearing loss. Am J Ind Med $48: 446-458$.

NIOSH. 1996. Preventing occupational hearing loss. A practical guide. Cincinnati, OH:DHHS, CDC, NIOSH.

NIOSH. 1998. NIOSH Criteria for a Recommended Standard: Occupational Noise Exposure, Revised Criteria 1998. Cincinnati, OH:DHHS, $\mathrm{CDC}, \mathrm{NIOSH}$

NIOSH. 2008. The sector-based approach. http://www.cdc.gov/NIOSH/ NORA/sector.html (accessed September 1, 2008)

OSHA. 1983 Occupational noise exposure. Standard 1910. 95. Regulations; Occupational Safety and Health Standards, US Department of Labor, Occupational Safety and Health Administration (OSHA).

Rabinowitz PM, Galusha D, Dixon-Ernst C, Slade MD, Cullen MR. 2007. Do ambient noise exposure levels predict hearing loss in a modern industrial cohort? Occup Environ Med 64:53-59.

Reilly MJ, Rosenman KD, Kalinowski DJ. 1998. Occupational noiseinduced hearing loss surveillance in Michigan. J Occup Environ Med 40:667-674.

Research Triangle Institute. 2004. SUDAAN Language Manual, Release 9.0. Research Triangle Park, NC:Research Triangle Institute.

El Dib RP, Verbeek J, Atallah A, Andriolo R, Soares B. 2006. Interventions to promote the wearing of hearing protection. The Cochrane Database of Systematic Reviews: No.: CD005234.pub005232.

Stephenson MR. 2009. Hearing Protection in the 21st Century: They're not your father's earplugs anymore. Seminars in Hearing 30:56-64.

Sulkowski W, Kowalska S, Lipowczan A, Prasher D, Raglan E. 1999. Tinnitus and impulse noise-induced hearing loss in drop-forge operators. Int J Occup Med Environ Health 12:177-182.

Tak S, Calvert GM. 2008. Hearing difficulty attributable to employment by industry and occupation: An analysis of the National Health Interview Survey-United States, 1997 to 2003. J Occup Environ Med 50:46-56. 